GEORGETOWN SCIENTIFIC RESEARCH JOURNAL
Volume Two Edition One Fall 2021

\title{
The Impacts on Well-being of Undergraduate College Students Serving in a Resident Assistant Role
}

Amanda J. Nemecek, Nancy Crowell Ph.D., and Joan B. Riley

$$
\text { MS, MSN, FNP-BC, FAAN }
$$




\title{
The Impacts on Well-being of Undergraduate College Students Serving in a Resident Assistant Role
}

\author{
Amanda J. Nemecek, Nancy Crowell, and Joan B. Riley \\ Department of Human Science, Georgetown University, Washington D.C. \\ E-mail: ajn63@georgetown.edu \\ https://doi.org/10.48091/gsr.v2i1.31
}

\begin{abstract}
Resident Assistants (RAs) are an integral part of the residential experience at colleges and universities, but little attention has been paid to how the RA position impacts student workers. This study examines the effect of the RA position on the well-being of undergraduate students working in the RA role. Three surveys collecting anonymous data on student well-being using the Keyes Flourishing Scale were distributed over the course of the fall 2018 academic semester. The SF-12 Health Questionnaire, the Sarason Social Support Questionnaire, the Deakin Coping Scale, and the Perceived Stress Scale were used to collect further data. Analysis was performed on data from 16 student RAs who responded to all three surveys. This diminished sample size prevented statistically significant data, but trends in the data are still evident. Social support remained positively correlated with well-being over the course of the semester. At the end of the semester, mental health was positively correlated with well-being while perceived stress was negatively correlated with well-being. Moreover, RAs in upperclassmen dorms and those with greater prior RA experience had nonsignificant yet overall higher levels of well-being throughout the semester. Though correlations are present between the well-being of student RAs and other factors in their lives, more data are needed to prove significance and further determine the relations between these factors.
\end{abstract}

Keywords: resident assistant, well-being, college, university

\section{Introduction}

The resident assistant (RA) position is an integral part of college residential community life and encompasses complex and varied responsibilities. Students hired as RAs provide peer support for fellow students living in campus residence halls and enforce school policies with an overall aim of fostering a community where residents can flourish personally and academically. RAs also act as first responders to student challenges, including substance abuse and physical and mental health crises. ${ }^{14,15}$ This demanding job creates tension in students employed as RAs, who must act as both an authority figure and a friendly peer. ${ }^{8}$ This tension means that student RAs may be hesitant to disrupt "social cohesion" by reporting rule breakers. ${ }^{16}$ The stress inherent in an
RA position might cause a negative impact on the well-being of students in this role.

Studies about RAs have largely focused on the benefits that RAs provide to a college community. These studies have identified factors contributing to burnout in $\mathrm{RAs}^{4}$, examined the influence of personality $^{2}$ and role conflict ${ }^{3}$ on RA job performance, identified skills transferable to careers and life post-graduation, ${ }^{6}$ and created tools with which to measure RA impacts on community development. ${ }^{9}$ In their 2018 paper, McLaughlin recognized the lack of research about self-care in student $\mathrm{RAs}^{10}$; however, research into RAs remains focused on job function and institutional benefits. More attention must be paid to students in RA positions, as these students generally face 
more stressful situations than their non-RA peers. ${ }^{11}$ The RA position is a social one, and evidence suggests that stronger social support systems are tied to better mental health. ${ }^{5}$ Coping strategies of student RAs in stressful situations might also influence well-being, as better self-care practices lead to lower stress susceptibility. ${ }^{13}$ However, factors correlated with higher levels of well-being in student RAs have not yet been well examined.

This study aimed to examine whether coping skills, perceived stress, and levels of social support improve or detract from the well-being of student RAs over the course of one 15-week semester. The information gained from this study can be used to promote well-being in the RA population. It was hypothesized that higher levels of social support would correlate with lower levels of perceived stress, higher well-being scores, and healthier coping strategies throughout the semester.

\section{Methods}

\subsection{Design}

This IRB approved study (2018-0489) was conducted from August 2018 through January 2019. A three-part survey design was used to assess the impacts of serving in an RA role, with surveys sent out pre-RA training, post-RA training, and post-semester. A senior staff member from the Office of Residential Education contributed to the design of the survey and approved its use.

\subsection{Participants}

Students older than 18 who were entering RA training at the start of the 2018-2019 academic year were invited to participate, and both new and returning RAs were included. This invitation was extended during an in-person information session conducted by the Principal Investigator on Day 2 of RA training, when informed consent was obtained through a written consent form. Surveys were distributed to participants via email: Survey 1 was sent out at the end of Day 2 of RA training (open for 3 days), Survey 2 was distributed at the end of RA training 8 days after the first survey was sent (open for 5 days), and Survey 3 was distributed at the end of final exams for the Fall 2018 semester (open 19 days over the semester break). Sixteen individuals $(\mathrm{n}=16)$ completed all three surveys; only their data were analyzed.

\subsection{Instruments}

Demographic data collected included participant age, gender, class year, previous RA experience, and residence hall placement (Table A1). Participant majors were collected but not presented as this could identify participants within the small population analyzed; given the small sample size, impacts of participant major on any of the measures of interest could not be determined. Additional data were gathered using the following instruments:

The Keyes Flourishing Scale (KFS) measures the general level of well-being in a person. ${ }^{7}$ This scale was used to track how the well-being of an RA changed over the course of a semester. Trends in well-being were compared against trends in other aspects of a student RA's life, namely social support, perceived stress, and coping strategies.

The Sarason Social Support Questionnaire (SSSQ) measures the level of social support present in a person's life. ${ }^{14}$ This scale was used to determine how social support fluctuated over the course of a semester. Given that greater social support is correlated with better mental health ${ }^{5}$, trends in social support were compared to those in well-being.

The Perceived Stress Scale (PSS) measures how an individual subjectively views stress in their life. ${ }^{1}$ This scale was used to determine the level of stress that student RAs subjectively experienced, with a focus on whether increased levels of perceived stress are correlated with decreased levels of well-being.

The Deakin Coping Scale (DCS) measures how an individual copes with problems that arise in their life. ${ }^{12}$ This instrument was used to determine how student RAs coped with stressors in their lives, and particularly to assess whether 
better coping strategies are correlated with higher levels of well-being in student RAs.

\subsection{Procedure}

Qualtrics served as the platform for survey distribution and data collection. The link to each Qualtrics survey was distributed to participants via email. Each participant initially created a password consisting of an animal and a three-digit number; participants input this password at the beginning of each survey. This was the only item that allowed follow-through of participant survey answers over the course of the study; thus, data were kept anonymous while allowing for trends in an individual's responses to be evaluated over time.

\subsection{Data Analysis}

At the study's conclusion, data were analyzed via SPSS. All data are presented anonymously and in aggregate (Table A2). Associations between the measures were analyzed using Pearson's Product Moment Correlations.

\section{Results}

Well-being was positively correlated with social support throughout the semester (Table 1). Well-being was positively correlated with coping skills in the first and second surveys and inversely correlated with perceived stress in the third survey (Table 1). Individual levels of well-being remained stable over the course of the study.

Although not significant, there was an incidental finding of lower levels of well-being in student RAs placed in first year residence halls compared to the well-being of RAs in other residence halls. Results also showed that student RAs with two or more years of prior RA experience had nonsignificant but overall higher levels of well-being compared to student RAs with less prior RA experience.
Table 1. Pearson's Correlations between Student RA Well-Being and Social Support, Perceived Stress, and Coping Skills Across a Semester.

\begin{tabular}{llll}
\hline & $\begin{array}{l}\text { KFS } \\
\text { Time } 1\end{array}$ & $\begin{array}{l}\text { KFS } \\
\text { Time 2 }\end{array}$ & $\begin{array}{l}\text { KFS } \\
\text { Time 3 }\end{array}$ \\
\hline SSSQ & $.682^{* *}$ & $.565^{*}$ & $.527^{*}$ \\
PSS & -.479 & -.492 & $-.519^{*}$ \\
DCS & $.571^{*}$ & $.633^{* *}$ & .266 \\
\hline${ }^{*} \mathrm{p}<.05 .{ }^{* *} \mathrm{p}<.01$. & &
\end{tabular}

\section{Limitations}

This study was limited by its small sample size, as only 16 student RAs responded to all three surveys. Additionally, all participants were enrolled at the same university, leading to potential uniformity among subjects. Response bias may be present as participants who responded to all three surveys might have higher baseline levels of wellbeing. Follow-through would likely be increased with outside incentive to participate, which was not provided in this study.

\section{Discussion}

Causality cannot be determined through this study. However, it can be concluded that there is a correlation between higher levels of social support and higher levels of well-being in student RA populations throughout a semester. This correlation may exist because stronger social support systems are linked to better mental health ${ }^{5}$, or there could be a third influencing factor not yet discovered. Better coping strategies were correlated with higher well-being during and just after RA training, but not at the end of the semester. Higher levels of perceived stress were inversely correlated with higher levels of wellbeing only at the end of the semester. A larger study with more diverse participants is needed to validate these findings and ensure significance. 
This study suggests a relationship between years of prior RA experience and well-being (Figure A2 and Table A4). It also suggests a relationship between residence hall placement and well-being (Figure A1 and Table A3); this is consistent with Hardy et al.'s finding that student RAs in first year residence halls face higher levels of burnout. ${ }^{4}$ Further research should examine the factors influencing well-being for returning versus new RAs, as this information can be used as a recruitment tool to improve RA retention rates.

\section{Conclusions}

As student RAs are often at the frontlines of student support, universities must take measures to ensure the students in these RA roles are able to flourish. This is necessary not only to preserve the functionality of the RA role, but also to preserve the well-being of students in these roles. The findings of this study indicate that RA programs should foster strong social support networks for their student RA communities to improve overall well-being. This study also suggests that universities should teach healthy coping strategies to their student RAs at the beginning of the semester and help student RAs recognize and reduce perceived stress at the end of the semester. Student RAs work an incredible amount to promote the well-being of students living in university residence halls while serving university interests. It is thus imperative that, in turn, universities care for the well-being of their RAs.

\section{Acknowledgements}

The authors would like to thank the Georgetown University Office of Residential Living for their support of this study alongside their input regarding survey questions. The authors would also like to thank all the student resident assistants who participated in this study.

\section{References}

1. Cohen, S., Kamarck, T., \& Mermelstein, R. (1994). Perceived stress scale. Measuring stress: A guide for health and social scientists. Retrieved from
http://www.mindgarden.com/documents/Perceive dStressScale.pdf

2. Deluga, R. J., \& Masson, S. (2000). Relationship of resident assistant conscientiousness, extraversion, and positive affect with rated performance. Journal of Research in Personality, 34(2), 225-235.

3. Everett, D. D., \& Loftus, Z. V. (2011). Resident Assistants as Rule Enforcers Versus Friends: An Exploratory Study of Role Conflict. Journal of College E University Student Housing, 37(2).

4. Hardy, S. E., \& Dodd, D. K. (1998). Burnout among University Resident Assistants as a Function of Gender and Floor Assignment. Journal of College Student Development, 39(5), 499-501.

5. Hefner, J., \& Eisenberg, D. (2009). Social support and mental health among college students. American Journal of Orthopsychiatry, 79(4), 491.

6. Huffman, L. C., \& Lefdahl-Davis, E. M. (2019).

A Pivotal Point in Identity

Development: The Impact of the Resident Assistant Experience. Growth: The Journal of the Association for Christians in Student Development, 18(18), 4.

7. Keyes, C. L. (2009). Brief description of the mental health continuum short form (MHC-SF). Retrieved from https://www.aacu.org/sites/default/files/MHCSFEnglish.pdf

8. King, J. J., Borsari, B., \& Chen, J. (2010). Resident assistant and college students' perceptions of alcohol use. Addictive behaviors, 35(6), 640-643.

9. Manata, B., DeAngelis, B. N., Paik, J. E., \& Miller, V. D. (2017). Measuring critical aspects of the resident assistant role. Journal of College Student Development, 58(4), 618-623.

10. McLaughlin, W. G. (2018). Overloaded and overlooked: Improving resident advisors' self-care. Journal of American College Health, 66(8), 831-833.

11. Miller, C. J., \& Conyne, R. K. (1980). Paraprofessional Problems: A Comparison of Residence Hall Paraprofessionals and Regular Students. Journal of College and University Student Housing, 10(1), 10-12.

12. Moore, K. A. (2003). The Deakin coping scale: strategies for the management of demands. The Australian Journal of Advanced Nursing, 21(2), 13.

13. Nowack, K. M., Gibbons, J. M., \& Hanson, A. L. (1985). Factors affecting burnout and job 
performance of resident assistants. Journal of College Student Personnel, 26(2), 137-142.

14. Sarason, I. G., Sarason, B. R., Shearin, E. N., \& Pierce, G. R. (1987). A brief measure of social support: Practical and theoretical implications. Journal of social and personal relationships, 4(4), 497510.

15. Thombs, D. L., Gonzalez, J. M. R., Osborn, C. J., Rossheim, M. E., \& Suzuki, S. (2015). Resident assistant training program for increasing alcohol, other drug, and mental health first-aid efforts. Prevention Science, 16(4), 508-517.

16. Thombs, D. L., Osborn, C. J., Rossheim, M. E., \& Suzuki, S. (2014). Attitudes associated with alcohol and marijuana referral actions by resident assistants. The journal of primary prevention, 35(6), 429-437. 


\section{Appendix}

Table A1. Demographic information for study participants $(n=16)$. Demographic information is presented both as a percentage (\%) of the total participants and as the number (n) of participants in each category.

\begin{tabular}{|c|l|l|}
\hline & $\%$ & $n$ \\
\hline Age & & \\
\hline 19 & 43.8 & 7 \\
\hline 20 & 18.8 & 3 \\
\hline 21 & 37.5 & 6 \\
\hline Gender & & \\
\hline Male & 43.8 & 7 \\
\hline Female & 56.3 & 9 \\
\hline Grade & & \\
\hline Sophomore & 50.0 & 8 \\
\hline Junior & 6.3 & 1 \\
\hline Senior & 43.8 & 7 \\
\hline Previous Years as an RA & & \\
\hline 0 & 50.0 & 8 \\
\hline 1 & 25.0 & 4 \\
\hline 2 & 25.0 & 4 \\
\hline Residency Hall Placement & & \\
\hline Freshman & 50.0 & 8 \\
\hline Mixed & 31.3 & 5 \\
\hline Primarily Upperclassmen & 18.8 & 3 \\
\hline & & \\
\hline
\end{tabular}


Table A2. Well-being in student RAs is correlated with various aspects of the student's life throughout the course of a semester. Correlational data was calculated using Pearson Correlation between well-being (KFS), social support (SSSQ), perceived stress (PSS), physical health (HQ-P), mental health (HQ-M), and coping skills (DCS) from surveys 1,2, and 3. Well-being was correlated with social support throughout the course of the semester. Well-being was correlated with coping skills in the first survey, but later that correlation became insignificant. In the third survey, well-being was inversely correlated with perceived stress and positively correlated with mental health.

*: Correlation is significant at the 0.05 level (2-tailed).

**: Correlation is significant at the 0.01 level (2-tailed).

\begin{tabular}{|c|c|c|c|c|c|c|}
\hline \multicolumn{2}{|l|}{ Survey 1} & KFS & SSSQ & PSS & HQ-P & HQ-M \\
\hline \multirow{2}{*}{ SSSQ } & Pearson Correlation & $.682^{\prime \prime}$ & & & & \\
\hline & Sig. (2-tailed) & .004 & & & & \\
\hline \multirow{2}{*}{ PSS } & Pearson Correlation & -.479 & $-.521^{*}$ & & & \\
\hline & Sig. (2-tailed) & .061 & .039 & & & \\
\hline \multirow{2}{*}{ HQ-P } & Pearson Correlation & -.129 & -.099 & .258 & & \\
\hline & Sig. (2-tailed) & .633 & .715 & .335 & & \\
\hline \multirow{2}{*}{ HQ-M } & Pearson Correlation & 292 & 392 & $-.655^{* \prime}$ & $-.696^{\prime \prime}$ & \\
\hline & Sig. (2-tailed) & .272 & .133 & .006 & .003 & \\
\hline \multirow{2}{*}{$\mathrm{DCS}$} & Pearson Correlation & $.571^{*}$ & .391 & -.108 & .240 & -.138 \\
\hline & Sig. (2-tailed) & .021 & .134 & .691 & .370 & .610 \\
\hline \multicolumn{3}{|l|}{ Survey 2} & & & & \\
\hline \multirow{2}{*}{ SSSQ } & Pearson Correlation & $.565^{*}$ & & & & \\
\hline & Sig. (2-tailed) & .023 & & & & \\
\hline \multirow{2}{*}{ PSS } & Pearson Correlation & -.492 & -.371 & & & \\
\hline & \begin{tabular}{|l|} 
Sig. (2-tailed) \\
\end{tabular} & .053 & .157 & & & \\
\hline \multirow{2}{*}{ HQ-P } & Pearson Correlation & -.106 & .067 & .113 & & \\
\hline & Sig. (2-tailed) & .696 & .806 & .677 & & \\
\hline \multirow{2}{*}{ HQ-M } & Pearson Correlation & .473 & .285 & $-.826^{\prime \prime}$ & -.444 & \\
\hline & Sig. (2-tailed) & .065 & .284 & .000 & .085 & \\
\hline \multirow{2}{*}{ DCS } & Pearson Correlation & $.633^{*+}$ & .349 & -.312 & .144 & .201 \\
\hline & Sig. (2-tailed) & .008 & .185 & .239 & .596 & .455 \\
\hline \multicolumn{3}{|l|}{ Survey 3} & & & & \\
\hline \multirow{2}{*}{ SSSQ } & Pearson Correlation & $.527^{*}$ & & & & \\
\hline & Sig. (2-tailed) & .036 & & & & \\
\hline \multirow{2}{*}{ PSS } & Pearson Correlation & $-.519^{*}$ & -.481 & & & \\
\hline & \begin{tabular}{|l|} 
Sig. (2-tailed) \\
\end{tabular} & .039 & .059 & & & \\
\hline \multirow{2}{*}{ HQ-P } & Pearson Correlation & .146 & .052 & .125 & & \\
\hline & Sig. (2-tailed) & .588 & .847 & .644 & & \\
\hline \multirow{2}{*}{ HQ-M } & Pearson Correlation & $.618^{*}$ & .382 & $-.848^{* \prime}$ & -.221 & \\
\hline & \begin{tabular}{|l|} 
Sig. (2-tailed) \\
\end{tabular} & .011 & .144 & .000 & .411 & \\
\hline \multirow{2}{*}{ DCS } & Pearson Correlation & .266 & .267 & .088 & .481 & .033 \\
\hline & Sig. (2-tailed) & .320 & .317 & .746 & .059 & .903 \\
\hline
\end{tabular}


Table A3. Multivariate Testsa: Comparison between Well-being and Residency Placement. There were no significant correlations between residency placement and well-being over the course of the semester (Wilks' Lambda: 0.583). There were overall higher levels of well-being in student RAs placed in primarily upperclassman residency halls compared to mixed or freshman residency halls, with student RAs in freshman residency halls consistently having the lowest levels of well-being. See Figure A1 for graphical representation of data.

\begin{tabular}{|l|l|l|l|l|l|l|}
\hline Effect & Value & F & Hypothesis df & Error df & Sig. \\
\hline Wellbeing & Pillai's Trace & .103 & $.692^{\mathrm{b}}$ & 2.000 & 12.000 & .519 \\
\cline { 2 - 8 } & Wilks' Lambda & .897 & $.692^{\mathrm{b}}$ & 2.000 & 12.000 & .519 \\
\cline { 2 - 8 } & Hotelling's Trace & .115 & $.692^{\mathrm{b}}$ & 2.000 & 12.000 & .519 \\
\cline { 2 - 8 } & Roy's Largest Root & .115 & $.692^{\mathrm{b}}$ & 2.000 & 12.000 & .519 \\
\hline Wellbeing * & Pillai's Trace & .210 & .764 & 4.000 & 26.000 & .558 \\
\cline { 2 - 7 } & Wilks' Lambda & .796 & $.726^{\mathrm{b}}$ & 4.000 & 24.000 & .583 \\
\cline { 2 - 8 } & Hotelling's Trace & .249 & .685 & 4.000 & 22.000 & .610 \\
\cline { 2 - 7 } & Roy's Largest Root & .213 & $1.386^{\mathrm{c}}$ & 2.000 & 13.000 & .285 \\
\hline
\end{tabular}

a. Design: Intercept + D9num

Within Subjects Design: Wellbeing

b. Exact statistic

c. The statistic is an upper bound on $\mathrm{F}$ that yields a lower bound on the significance level. 
Table A4. Multivariate Tests ${ }^{\text {a }}$ Comparison between Well-being and Years as an RA. There were no significant correlations between number of previous years of student RA experience and well-being over the course of the semester (Wilks' Lambda: 0.491). There were overall higher levels of well-being in student RAs who had two or more years prior experience as an RA compared to one-year prior experience or no years prior experience. See Figure A2 for graphical representation of data.

\begin{tabular}{|c|c|c|c|c|c|c|}
\hline \multicolumn{2}{|l|}{ Effect } & Value & $\mathrm{F}$ & Hypothesis df & Error df & Sig. \\
\hline \multirow[t]{4}{*}{ Wellbeing } & Pillai's Trace & .145 & $1.016^{b}$ & 2.000 & 12.000 & .391 \\
\hline & Wilks' Lambda & .855 & $1.016^{b}$ & 2.000 & 12.000 & .391 \\
\hline & Hotelling's Trace & .169 & $1.016^{\mathrm{b}}$ & 2.000 & 12.000 & .391 \\
\hline & Roy's Largest Root & .169 & $1.016^{b}$ & 2.000 & 12.000 & .391 \\
\hline \multirow[t]{4}{*}{ Wellbeing * D8 } & Pillai's Trace & .240 & .885 & 4.000 & 26.000 & .487 \\
\hline & Wilks' Lambda & .761 & $.879^{b}$ & 4.000 & 24.000 & .491 \\
\hline & Hotelling's Trace & .314 & .864 & 4.000 & 22.000 & .501 \\
\hline & Roy's Largest Root & .313 & $2.031^{\mathrm{c}}$ & 2.000 & 13.000 & .171 \\
\hline
\end{tabular}

a. Design: Intercept + D8

Within Subjects Design: Wellbeing

b. Exact statistics

c. The statistic is an upper bound on $\mathrm{F}$ that yields a lower bound on the significance levels. 


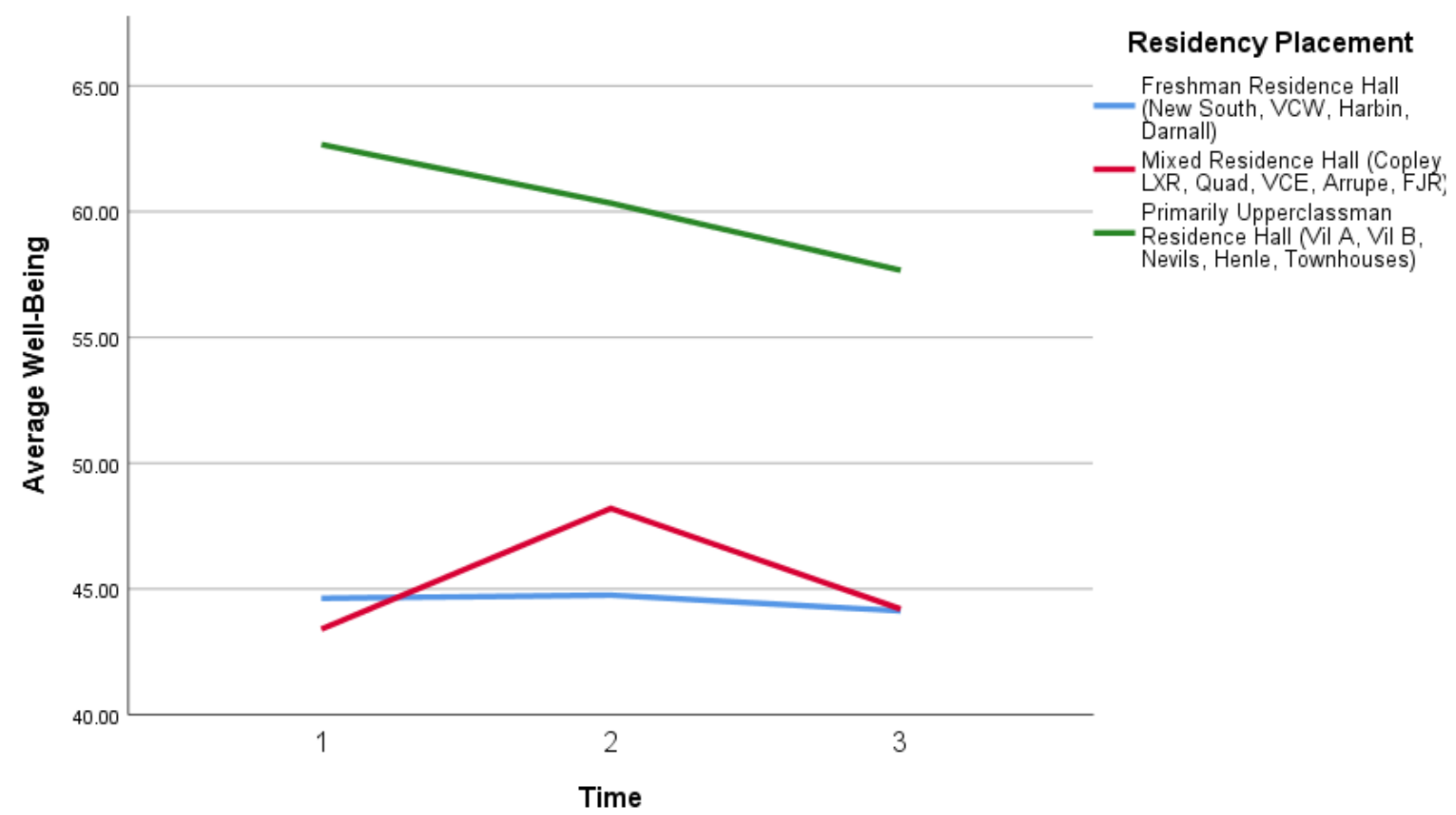

Figure A1. Well-being over time compared to residency placement of the student RA. There were no significant correlations between residency placement and well-being over the course of the semester (Wilks' Lambda: 0.583). There were overall higher levels of well-being in student RAs placed in primarily upperclassman residency halls (green line) compared to mixed (red line) or freshman (blue line) residency halls, with student RAs in freshman residency halls having the consistently lowest levels of well-being. 


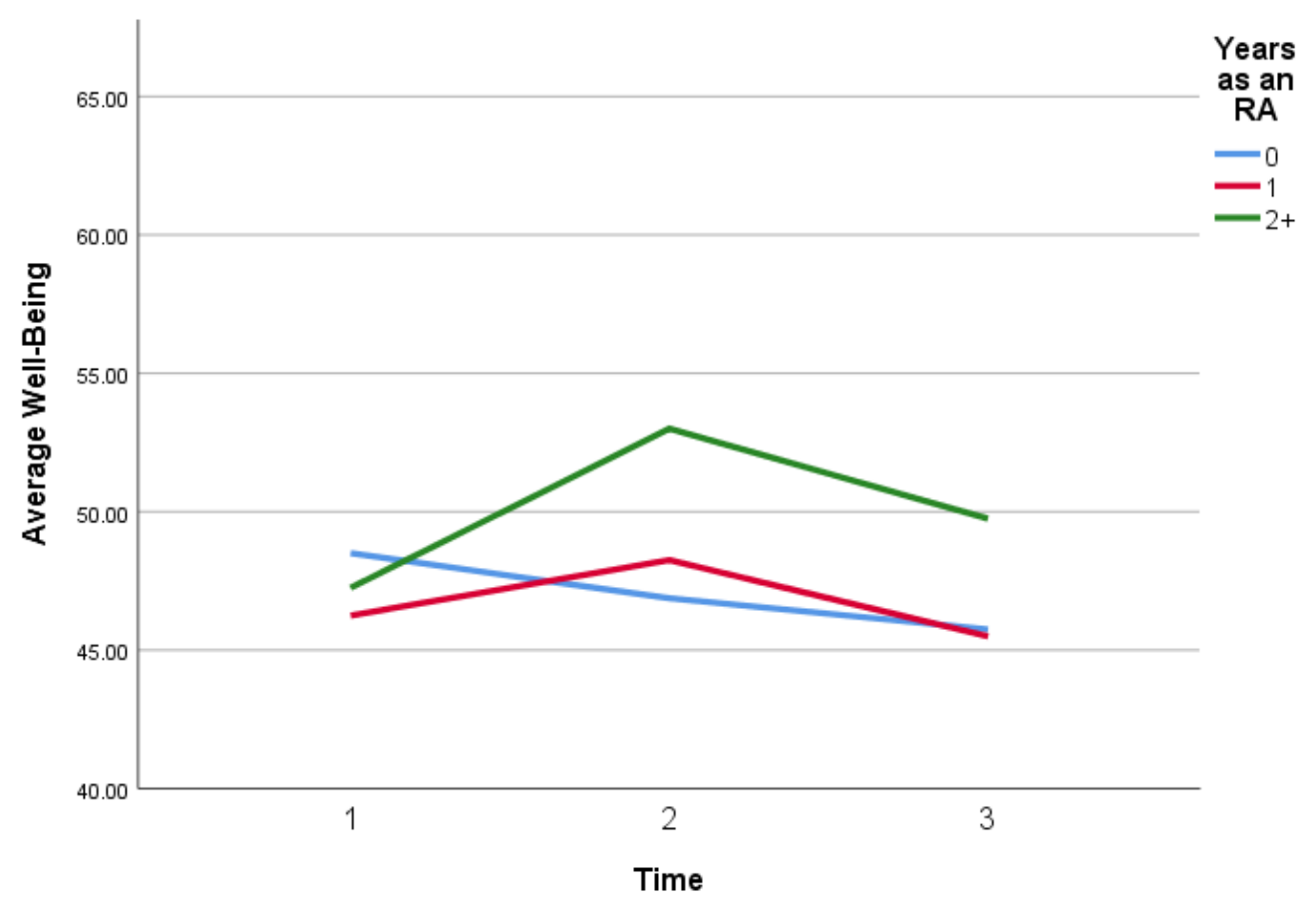

Figure A2. Well-being over time compared to previous years of experience as a student RA. There were no significant correlations between number of previous years of student RA experience and well-being over the course of the semester (Wilks' Lambda: 0.491). There were overall higher levels of well-being in student RAs who had two or more years prior experience as an RA (green line) compared to one-year prior experience (red line) or no years prior experience (blue line). 


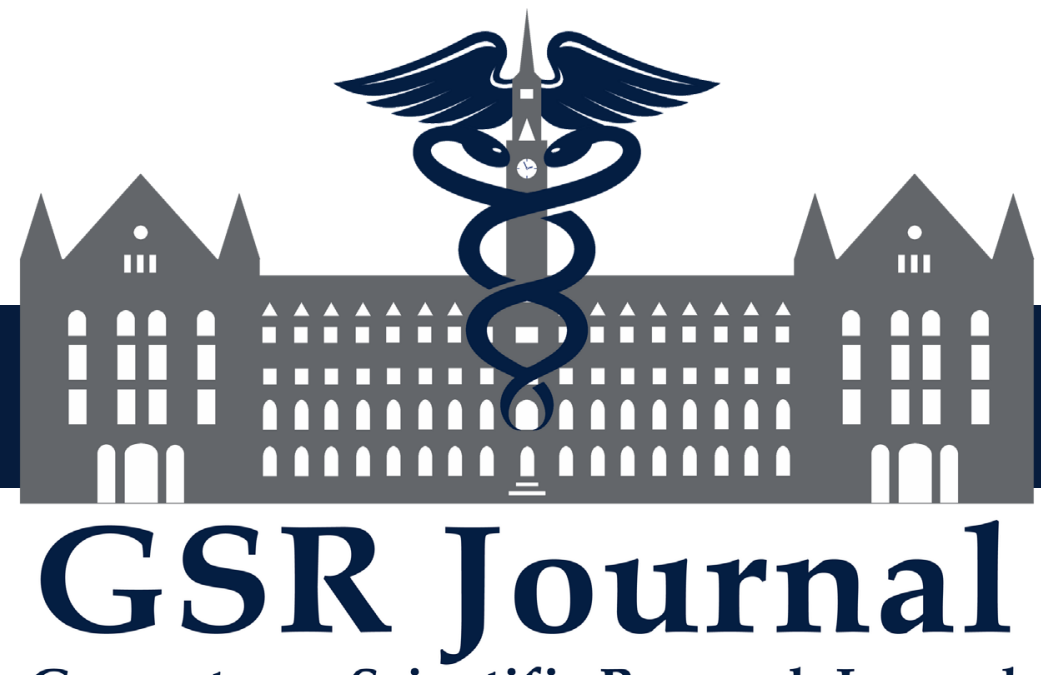

Georgetown Scientific Research Journal 